\title{
A quem pertence conhecimento e cultura? \\ Uma reflexão sobre o discurso de legitimação do direito de autor
}

Karin Grau-Kuntz*

Resumo Centrando-se no do discurso tradicional de legitimação do direito de autor e na disciplina da análise literária a autora demonstra a impossibilidade de privatização do conhecimento e da cultura.

Palavras-chaves direito de autor, análise literária, cultura.

\section{Who owns knowledge and culture?}

\section{A reflection on discourse legitimating copyright}

\begin{abstract}
Focusing on the traditional discourse of the legitimation of copyright and on the discipline of literary theory the author demonstrates the impossibility of privatization of knowledge and culture.
\end{abstract}

Keywords copyright, literary theory, culture.

\section{Introdução}

O Editorial desta publicação, reportando ao fato de que as criações intelectuais protegidas por direitos de autor contêm elementos pessoais, econômicos e socioculturais, destaca o impacto desse último elemento e recorda a atualidade das preocupações a ele referentes, como pauta moderna de discussão necessária daqueles que trabalham com o instituto jurídico do direito de autor.

\footnotetext{
* Doutora em Direito pela Ludwig Maximilian Universität Coordenadora acadêmica e pesquisadora do Instituto Brasileiro de Propriedade Intelectual.
} 
$\mathrm{Na}$ exposição que se segue, partindo de uma perspectiva discursiva, tomarei como objeto os elementos supra mencionados contidos nas obras intelectuais, especialmente os de natureza pessoal e sociocultural, explorarei a atualidade da consideração deste último, propondo, por fim, em consonância com a perspectiva de trabalho escolhida, uma revisão do discurso de legitimação vinculado ao instituto jurídico.

\section{Sobre o discurso de legitimação}

Uma reflexão sobre o discurso de legitimação do direito de autor pede, de plano e por óbvio, algumas considerações, mesmo que breves, sobre a questão da legitimação do Direito.

O que é legitimação e por que nos preocupamos em legitimar o direito?

Partindo da segunda questão proposta, nós nos preocupamos em legitimar o Direito porque afirmar que "Direito é direito (no sentido de algo positivo, correto) só porque é Lei" só bastaria para explicar a obediência do destinatário das normas quando movido pelo temor de consequências, e não o seu convencimento no sentido de que o feixe de regras não é apenas Direito em acepção legal, mas também Direito "direito" (no sentido de positivo, correto). A palavra legitimação, então, expressa o convencimento de que o comportamento determinado na Lei não se esgota em uma obrigação legal, cujo descumprimento resulta em sanção, mas que também é comportamento socialmente desejado, positivo. Em outras palavras, é o convencimento jurídico o elemento que permite que a lei seja "sentida" pelo destinatário não só como coerção, mas também como Direito "direito".

A formação do convencimento jurídico implica a satisfação de três níveis de validade da norma, quais sejam ${ }^{1}$ :

a) do da validade jurídica, ou validade do dever ser, quando a norma foi produzida em consonância com as regras de produção legal (legalidade),

b) do da validade fática, ou validade do ser, que circunscreve o cumprimento fático da disposição legal, e

c) do da validade moral, oriunda do reconhecimento social da norma por seus destinatários.

A interação harmônica entre estes três níveis da validade leva à formação da consciência jurídica que, a seu turno, transforma a obediência devida no âmbito de validade jurídica (validade do dever-ser) em convencimento jurídico.

Porque mencionei acima a validade moral urge necessário frisar - bem sei que alguns mais afoitos reagirão de imediato à mera alusão ao vocábulo "moral" - que não estou aqui a dizer que a moral dos povos constituiria, em uma relação hierárquica, uma instância superior ao Direito.

\footnotetext{
${ }^{1}$ Estou aqui a me reportar ao trabalho de RÜTHERS, 2005, p. 231
} 
Moral e Direito manifestam-se de formas distintas e independentes, isto é, o destinatário de uma lei não é compelido a respeitá-la com o recurso a valores morais, mas sim a valores jurídicos. Mas ele não a respeitará - ou assim esperamos que seja, se cremos em um estado de direito, e não em um estado de terror - só porque teme sanções, mas porque está convencido que a Lei é Direito "direito", isto é, que os valores jurídicos são não só valores "legais", mas também "direitos" (no sentido de corretos, positivos), o que implica necessariamente que esteja convencido não só da validade jurídica da norma, mas também de sua validade moral ${ }^{2}$. Então, não obstante faltar relação hierárquica entre Direito e Moral, não obstante a independência de um frente ao outro, encontramos entre eles um vínculo difuso, mínimo, que se manifesta em suas gêneses como sistemas, isto é, no homem como ser social e ético ${ }^{3}$.

Tendo-se em conta a perspectiva dos níveis de validade das normas, resta simples compreender a importância daquilo que acima denominei discurso de legitimação, isto é, dos argumentos que suportam e fomentam a formação de consciência e convencimento jurídico.

No que toca o tema desta exposição, a reflexão que proponho cumprir a seguir compreenderá a análise crítica dos elementos que dão corpo ao discurso de legitimação tradicional do direito de autor e questionará sua adequação frente às transformações na estrutura da sociedade de informação.

\section{O discurso de legitimação do direito de autor}

1. O discurso tradicional de legitimação do direito de autor é construído a partir de dois elementos, quais sejam autor e obra, e em consideração à interação desses dois elementos.

A definição de autor pressupõe o elemento obra, i.e pressupõe alguém - o autor - que algo cria a obra. O vocábulo autor não reporta, assim, a um estado, mas antes a uma relação entre um sujeito e sua criação intelectual. No mesmo sentido a definição do vocábulo obra pressupõe a consideração da figura do autor.

A diferença na relação de definição do autor em pressuposição à obra, e da obra em pressuposição ao autor, é fornecida pelo elemento da expressão da individualidade: porque a obra conteria a expressão da individualidade do autor, este exerceria um poder sobre aquela e ela, por consequência, estaria sujeita àquele. Nessa relação de sujeição calcada na individualidade de alguém, base do entendimento de que o autor teria um direito de propriedade

\footnotetext{
${ }^{2}$ O exemplo clássico aqui é o do episódio da Lei Seca nos Estados Unidos da América. Como reflexo do pensamento puritano foram oficialmente proibidos em 1919 a fabricação, o comércio, a importação ou exportação de bebidas alcoólicas naquele país. Treze anos após a sua promulgação esta lei foi abolida. O fiasco da Lei Seca deveu-se ao fato de ter sido ela amplamente ignorada pelos cidadãos americanos. O conteúdo da norma não foi reconhecido pelos seus destinatários. Apesar da ética puritana, apesar dos conhecidos efeitos negativos à saúde, o consumo de bebidas alcoólicas não era --- e continua não sendo --- compreendido como moralmente abominável.

${ }^{3}$ Vide ainda RÜTHERS, 2005, p. 276.
} 
em relação à sua obra ${ }^{4}$, identificamos o ponto de partida na estrutura do pensamento: o homem considerado em sua individualidade..$^{5}$

Isto posto, é hora de introduzir o elemento originalidade, que desponta no raciocínio como um instrumento delimitador, circunscrevendo no âmbito do gênero das criações intelectuais a categoria de criações intelectuais que podem ser protegidas pelo direito de autor ou, ainda, a categoria das obras intelectuais ${ }^{6}$.

Por fim, ainda vinculado ao discurso de legitimação do instituto jurídico em questão, é necessário recordar que em seu estado natural a informação - a menor unidade da obra - é livre, i.e. ela se caracteriza por sua ubiquidade ou, em outras palavras, por sua capacidade de estar ao mesmo tempo em diversos lugares. Com a previsão de um direito exclusivo o legislador intervém no estado natural da informação, criando uma possibilidade de controle em relação ao seu aproveitamento econômico. Essa intervenção no estado natural da informação implica, a se turno, um custo social, custo que seria compensando com o enriquecimento cultural.

Em síntese, o discurso tradicional de legitimação do direito de autor vê, na obra intelectual, necessariamente uma criação original, sujeita ao autor, porque contém traços de sua individualidade o que, por sua vez, legitima a garantia de um direito exclusivo deste em relação àquela, exclusividade mediatamente positiva, posto que compensado o seu custo social com o fomento cultural.

2. É interessante notar que essa formulação tradicional do discurso de legitimação - formulação que vem sendo repetida por muitas gerações - ignora completamente o elemento comunicativo das criações intelectuais originais, elemento que, por sua vez, é pressuposto da própria estrutura do instituto jurídico do direito de autor, e que vem expressamente fincado na definição legal de obras protegidas como aquelas expressas de alguma maneira ${ }^{7}$.

A definição normativa de obra não se deixa assim esgotar na relação entre criador e criação original, mas ainda pressupõe um elemento comunicativo, isto é um conteúdo expresso que, por sua vez, deverá necessariamente estar dirigido e voltado a alguém, quem seja, o público.

No momento em que introduzirmos o elemento comunicação ao discurso de legitimação do direito de autor ou, em outras palavras, no momento que considerarmos o valor comunicativo da obra, romperemos necessariamente com a construção dualista tradicional e, especialmente, como

\footnotetext{
${ }^{4}$ Em outra ocasião expliquei porque ao autor não é garantido direito de propriedade algum, pelo contrário, o direito exclusivo só lhe garante prerrogativas de controle de acesso à obra. Vide aqui GRAU-KUNTZ, 2010.

${ }^{5}$ É possível que cause surpresa, especialmente àqueles que ainda não se preocuparam em refletir sobre a premissa, mas a consideração do homem em sua individualidade como ponto de partida de sua relação com as criações intelectuais não é condição sine qua non. Nada obsta, por exemplo, considerarmos o homem em sua condição de ser social, ou ainda poderíamos partir da consideração da limitação criativa natural do homem, no sentido de que nada do que ele cria poderá ser compreendido como criação, se anteriormente não houver sido fornecido um contexto cultural que permita que se compreenda a criação como tal. É importante ter em mente que a consideração do homem em sua individualidade traduziu uma opção ideológica, que teve suas razões em um momento histórico determinado.

${ }^{6}$ Nos limites desse ensaio não poderei me estender na erosão do critério da originalidade - quanto menor o grau de originalidade, maior o espectro de criações intelectuais que podem ser consideradas como obras intelectuais - e não poderei enveredar na questão de determinação do vocábulo (o que é originalidade?). Esses aspectos já foram tratados em outra ocasião por GRAU-KUNTZ, 2010.

${ }^{7}$ Vide artigo 7 da Lei 9.610/98
} 
demonstrarei a seguir, seremos forçados a nos distanciar da ideia de sujeição da obra exteriorizada à individualidade do autor. Isto porque considerar o valor comunicativo da obra pressuporá trazer ao bojo do discurso de legitimação o elemento do público como destinatário da exteriorização e, por consequência, a aceitar a inevitável interação da obra com aquele, que a interpretará (i. é. a recriará) $)^{8}$, o que pressupõe, por sua vez, que esta não esteja cimentada à individualidade de alguém autor. E essa perspectiva implicará ainda, necessariamente, como a seguir demonstrarei, a compreensão dinâmica do processo de enriquecimento cultural e na necessária conclusão de que conhecimento e cultura não pertencerão, jamais, a ninguém.

3. Partindo da compreensão tradicional do vínculo entre autor e obra, no sentido de que esta estaria vinculada àquele por conter os traços de sua individualidade, noto que tal construção não se caracterizou por ser tema exclusivo do direito de autor. Pelo contrário, foi ainda tema de preocupações e discussões no âmbito da análise literária. Nesse sentido, apesar de distintos em suas estruturas e objetivos, a coincidência desses elementos faz produtivo e didático um breve recurso à discussão literária e, especialmente, a uma de suas grandes questões de análise, que versou sobre a necessidade ou não do recurso à biografia (ou intenção) do autor - recurso que podemos traduzir como manifestação de sua individualidade - na procura do sentido dos textos.

Voltando os olhos à análise literária, situo a referência a biografia do autor em sua conotação romântica, característica dos séculos XVIII/XIX, período que também coincidiu com a estruturação argumentativa tradicional do direito de autor ${ }^{9}$. E para ilustrar a discussão no âmbito literário, lanço a princípio mão de uma exposição do formalista russo Boris Tomasevskij (2000) que serviu de impulso para discussões posteriores, que culminam no conhecido e citado trabalho de Michel Foucault, "O que é um autor"10.

Lembrando que a pessoa do autor nem sempre esteve no alvo dos interesses do público ${ }^{11}-$ ou como elemento na busca do sentido do texto, TOMASEVSKJI $(2000$, p.50) situa as primeiras manifestações de um vínculo subjetivo entre autor e obra na encenação de alguns autores em torno de sua própria pessoa e, nesse sentido, ilustra o afirmado com as pessoas de Voltaire e Rousseau.

O artifício da encenação pessoal, ainda na linha de exposição do linguista russo, culminará no ápice do Romantismo que, na máxima expressão de subjetivismo, tinha as criações intelectuais como fruto de vida interior intensa do autor, desvinculada da objetividade da realidade externa. Aqui entra em cena a figura do poeta romântico que nos é corrente: sonhador, almejando um amor idealizado, frágil, morrendo na miséria para alcançar fama póstuma. Obra e autor despontam como unidade de encenação estética: o autor é protagonista de sua criação intelectual ou, em outras palavras, sua biografia e sua obra se fundem formando um todo.

\footnotetext{
${ }^{8}$ Não me estenderei aqui na determinação do conteúdo do vocábulo interpretação. Reporto o leitor a um comentário de minha autoria relativo a um texto do escritor Paulo Coelho, publicado em seu blog, ambos publicados no número 4 da Revista Eletrônica do IBPI, que pode ser acessado gratuitamente a partir da plataforma do IBPI, no endereço www.ibpibrasil.org. Da leitura do breve comentário o leitor poderá entender, sem que seja necessário lançar mão de explicações complexas, o que tenho em mente quando digo que o intérprete recria o conteúdo que lhe é comunicado pela obra.

${ }^{9}$ A título ilustrativo, lembro aqui do trabalho de Otto von Gierke, jurista alemão que contribuiu sobremaneira para o desenvolvimento das noções que envolvem o conceito de direito moral de autor.

${ }^{10} \mathrm{Eu}$ me refiro aqui à tradução alemã da exposição de Foucault, publicada no livro Texte zur Literaturtheorie der Gegenwart, organizado por KRIMMICH, RENNER, STIEGLER, 1996, p. 232-247.

${ }^{11}$ Vide aqui o excelente trabalho de CARBONI (2010)
} 
Os reflexos do clima romântico (subjetivista) na interação entre biografia e literatura, ainda explica TOMASEVSKJI (2000, p. 50), exigiam a figura de um autor que, em dissemelhança ao leitor, não estaria condenado ao cotidiano e à normalidade. Nesse sentido notava-se uma tendência de mitificação da biografia do autor o que, por sua vez, implicou na formação de uma legenda em torno dele (do autor), legenda que não se deixava confundir com a sua própria pessoa.

Entre pessoa privada e obra encontramos então uma figura biográfica cênica, uma figura com personalidade de (ou melhor como) autor.

Uma das preocupações de TOMASEVSKJI (2000) no trabalho em tela foi demonstrar que biografia privada e biografia cênica não se deixam confundir, o que restou evidente quando surge o poeta de profissão. Este, autor sem biografia encenada, expressa a sua criação sem a intermediação da construção cênica de personalidade de (ou como) autor. Com isso TOMASEVSKJI (2000, p. 61) não afirmava que esses autores não tivessem biografia. É óbvio que as tinham. Mas demonstrava que as biografias privadas só interessam àqueles preocupados em proceder a uma análise de cunho histórico-cultural. Elas não servem como elemento de interpretação da obra, posto serem documentais, sem a capacidade de esclarecer o poder comunicativo da obra, um pressuposto daquela e, assim, não se distinguindo das biografias de generais ou desportistas.

Chegando ao âmago do raciocínio, não será possível buscar na biografia pessoal (ou na individualidade do autor) o sentido da obra. A biografia que dá sentido à obra em seu aspecto estético (interpretativo), nos casos em que exista (há autores com ou sem biografias encenadas), não é a biografia $d o$ indivíduo autor, mas biografia construída com os mesmos elementos contidos no texto e, por essa razão, tão destacada do autor como pessoa como o é a própria obra.

4. No que toca à construção discursiva do direito de autor, que quer, mesmo após sua exteriorização, ver a obra ainda amplamente vinculada ao autor como pessoa, posto que nela encontraríamos expressão da individualidade daquele, não causa surpresa ter sido ela estruturada exatamente durante o período histórico altamente subjetivista e fomentador da biografia encenada. O que espanta é ver tal compreensão persistir imutável no âmbito do discurso jurídico por tanto tempo, enquanto há muito já foi rejeitada em outros âmbitos culturais ${ }^{12}$.

Note porém o leitor que com o afirmado não estou a negar qualquer vínculo do autor com a obra. A obra, porque criação intelectual de alguém, por certo trará sempre consigo os traços genéticos de seu criador. Mas o que se afirma não implica a conclusão de que a criação intelectual original só ganharia sentido em reporte aos traços genéticos que contém (a individualidade do autor). A diferença aqui é sutil; compreendê-la, como demonstrarei a seguir, será, no momento em que trazemos à consideração o elemento comunicativo ao discurso de legitimação do instituto jurídico, fundamental.

Para sustentar o que acima afirmei, passo a lançar mão da reflexão do estruturalista checo Jan Mukarovsky (2000) que, em trabalho intitulado "A personalidade na arte", cuidou de afastar qualquer suspeita de que, na linha do que postulou Tomasevskji, ao negar ver na obra reflexos da individualidade do autor como indivíduo, estaria a considerar a pessoa do autor destacada da obra.

\footnotetext{
${ }^{12}$ Lembro aqui que o direito é tão fenômeno cultural como o é o ramo da análise literária.
} 
Mukarovsky, sem negar a importância do autor (aqui considerado em sua individualidade) como sujeito da obra, responsável por ela se distinguir dos objetos da natureza ou, em outras palavras, fonte do princípio de sua unidade, trouxe ao seu raciocínio o valor comunicativo da obra: o autor cria para comunicar, e quem comunica se dirige a alguém. No âmbito desse raciocínio a obra desponta situada entre dois sujeitos: o primeiro sujeito se caracteriza por oferecer algo (um conteúdo original), enquanto o segundo sujeito ocupa a posição de receptor do oferecido e, consequentemente de intérprete do conteúdo original.

A relação fluida entre sujeito-conteúdo-sujeito não poderá ser interrompida sob pena de perda do caráter comunicativo do conteúdo, caráter que faz dele, do conteúdo, uma obra, seja no sentido literário ou, eu acrescento, no sentido jurídico. A criação intelectual não poderá, então, depois de exteriorizada, reportar a individualidade do autor, sob pena de não permitir ser interpretada pelo destinatário.

Aqui, e ainda em consideração à discussão literária, é chegado o momento de trazer à baila o elemento intenção do autor.

$\mathrm{O}$ que os textos dizem? Aquilo que o autor tinha como intenção dizer ou aquilo que o destinatário deles retira (interpreta)?

Se os textos só dizem o que os autores querem que eles digam - ou seja, se estão cimentados na individualidade daqueles - então os leitores não poderão trazer, no momento da leitura dos textos, qualquer elemento vinculado às suas formas de compreensão dos textos, i.e. não poderão interpretá-los. Antes, deverão recorrer aos autores, perguntando a eles o que intencionaram dizer. Nessa situação os textos não interagem com os leitores: são blocos estáticos ${ }^{13}$, presos a um único sentido "correto", qual seja aquele que os autores lhes deram.

Foi o distanciamento do elemento intenção do autor, e a valorização da função comunicativa dos textos, que levaram os franceses Roland Barthes e, logo em seguida Michel Foucault a, quase cinquenta anos após a publicação do trabalho de Tomasevskij, e vinte cinco anos depois da publicação do de Mukarovsky, declararem a "morte do autor" ${ }^{14}$. Nestes trabalhos nos deparamos com discursos calcados em uma outra dualidade, que não mais aquela baseada na relação de sujeição da obra à personalidade/individualidade/intenção do autor, mas que consideravam apenas (ou melhor, principalmente), a obra em sua relação comunicativa com o público a que se destina, em ampla liberdade interpretativa.

Aqui não é o momento de me aprofundar nos trabalhos de Barthes e Foucault, mas para fins de completude julgo importante destacar que o radicalismo dos franceses - sem que a palavra radicalismo seja aqui empregada em sentido negativo - veio posteriormente ser abrandado pelo professor italiano de semiótica Umberto Eco.

\footnotetext{
${ }^{13}$ Eles só não seriam blocos estáticos em relação aos seus autores, que seriam os únicos legitimados a renovarem o sentido dos seus textos. Isso leva a uma inferência um tanto absurda: se só o autor é legitimado a renovar o sentido dos textos, e se a sociedade está em constante mutação cultural, então após a morte dos autores os textos deixariam de cumprir qualquer função comunicativa, posta a impossibilidade de se perguntar aos autores como devem ser compreendidos frente às transformações dos valores socioculturais.

14 “A morte do autor" é o título do trabalho do francês Roland Barthes, que Michel Foucault conhecia, apesar de não mencioná-lo no seu "Quem é o autor". Vide neste sentido a introdução que procede ao texto de Michel Foucault em tela, (1996, p. 194)
} 
Este, em uma coletânea de textos publicada pela primeira vez em 1990 e intitulada "Os limites da interpretação" "15, e ainda partindo de uma compreensão aberta da obra, isto é, em consideração a seu potencial comunicativo, receptiva a várias interpretações, defendeu limites interpretativos do texto, limites que encontramos no próprio texto, em sua manifestação como um organismo, como um sistema de relações.

Reconhecer limites interpretativos ao texto não significa, porém, afirmar que eles dizem o que os autores queriam (ou querem) que dissessem (que digam), mas antes que eles só podem dizer aquilo que pode estar contido em sua estrutura orgânica. Insistindo, as obras são abertas a inúmeras interpretações e em momento algum Eco defende que os limites dos textos estaria na intenção pessoal do autor (na individualidade do autor projetada no texto), mas antes, e aqui vejo o radicalismo dos franceses anteriormente citados abrandado, o italiano tem em conta no processo de interpretação procedido pelo leitor a presença da figura de um autor-modelo, um sujeito de uma intenção linguística despersonalizada, isto é, uma intenção que, cum grano salis, estaria vinculada ao âmbito dos limites dos significados das palavras escolhidas por aquele ${ }^{16}$.

Termino aqui o breve excurso pela análise literária: a noção dualista romântica e subjetivista, de que o significado do texto estaria expresso na individualidade do autor, foi ultrapassada no início do século passado, dando espaço à compreensão do texto (a obra) como produto de um esforço comunicativo de alguém que, como tal, estará necessariamente aberto a ser recriada (interpretada) por seus destinatários. Sem aqui argumentar com a "morte do autor", a função deste último é limitada em relação à obra no sentido de ser este a fonte de sua unidade. Como os filhos, as obras trazem os traços genéticos dos pais, mas nem por isso são manifestação da individualidade daqueles, mas antes são autônomas e fadadas a cumprirem com seus destinos comunicativos.

5. Isto posto, acredito restar claro ao leitor a importância da consideração do valor comunicativo da obra e, consequentemente, a necessidade de consideração dos destinatários da comunicação no discurso de legitimação do direito de autor (mesmo porque, como já notei, o valor comunicativo das obras intelectuais é pressuposto legal de proteção). Em outras palavras, urge revisar no âmbito jurídico o discurso de legitimação do direito de autor.

Porém, dessa conclusão não é ainda possível tirar consequência alguma para a prática vinculada ao direito de autor e, ademais, e principalmente, para responder a pergunta que os organizadores desta publicação propuseram, ou seja, a quem pertencem conhecimento e cultura?

Eu relembro aqui que o discurso calcado na dualidade "autor / obra, como reflexo da individualidade daquele" não é simplesmente lançando no espaço, mas antes empregado embutido em uma "equação" que envolve a intervenção do legislador no estado natural da informação e a contrapartida social, expressa no enriquecimento cultural.

\footnotetext{
${ }^{15}$ Assim creio ser o título da coletânea em português. Eu usei aqui a tradução alemã: ECO, Humberto. Die Grenzen der Interpretation.

${ }^{16}$ Nesse sentido ECO (p. 144), lembra que não seria correto interpretar um texto como se procede a "leitura" do futuro com a borra do café turco. Ademais, temendo dificuldades de compreensão do raciocínio de Eco, mesmo porque o apresentei aqui de forma muito simples e incompleta, noto que não seria correto se deixar tentar em querer ver na forma de expressão do texto, no sentido em que expressão é empregada no discurso do direito de autor, a "intenção linguística" de Eco. O professor de semiótica italiano, que não fala em intenção - quem usa o termo sou $e u$ - parte de um escopo despersonalizado dessas limitações. Por sua vez o recurso a forma de expressão no âmbito do direito de autor ocorre sempre em um contexto personalizado.
}

Liinc em Revista, v.7, n.2, setembro, 2011, Rio de Janeiro, p. 405 - 415 - http://www.ibict.br/liinc 
Sob essa perspectiva a compreensão dualista-individual do discurso tradicional de legitimação do direito de autor leva a inferir que o valor cultural da obra, por ser ela emanação em relação de dependência com o autor, ou com sua psique, poderia ser encontrado no próprio ato da criação intelectual. A perspectiva que se adota nesse raciocínio é estática: em mente temos o homem destacado de seu contexto social, e somos obrigados a reconhecer no ato de criação original, em si considerado, um plus social.

Ocorre, porém, que o simples ato de criação intelectual não representa plus social algum, uma vez que a contrapartida do enriquecimento cultural pressupõe a recepção do conteúdo da criação pelo público, sua interação e recriação por ele (interpretação, no sentido a que reportei o leitor na nota 8, supra).

O plus cultural, a contrapartida à intervenção do legislador na natureza da informação, não encontramos assim no ato de criação em si considerado, mas no processo de interação da criação com seus destinatários, porque, como espero ter demonstrado com o recurso à discussão no âmbito da análise literária, o valor cultural da obra não está na individualidade do autor, mas antes no seu potencial comunicativo.

Conhecimento e cultura não podem pertencer a ninguém. $\mathrm{O}$ conhecimento é um dos elementos que compõe a noção de cultura e essa, por sua vez, pressupõe uma série de relações dinâmicas de "toma lá, dá cá", como o processo de absorção da obra pelo público deixa ilustrar.

É necessário insistir aqui que com o exposto não estou a afastar a figura do autor desse processo dinâmico, que caracteriza o conceito de cultura. O que procuro frisar é que o enriquecimento cultural, ao contrário do que a expressão "patrimônio cultural" parece sugerir, não se limita a um mero ato de contribuição individual. Patrimônio cultural não é um arquivo dotado de mero valor quantitativo, onde os autores depositam suas criações e são premiados pelo próprio ato de depósito.

Nesse sentido, se a garantia patrimonial de controle exclusivo relativo às condições de acesso à obra se justifica pela necessidade de oferecer aos autores uma possibilidade de autodeterminação patrimonial - aqui o elemento econômico vinculado à noção de direito de autor, ao qual o editorial dessa revista se refere (vide supra, I) - e se algumas outras prerrogativas são garantidas em consideração ao fato de as obras trazerem em si um vínculo genético com seus criadores, nada justifica sequer cogitar serem eles titulares de direitos de controle sobre a interação cultural de suas obras.

6. O rompimento com o discurso tradicional de legitimação do direito de autor e sua consequente e necessária revisão, que aqui defendo com veemência, trará consigo consequências práticas significativas e salutares.

Em conta do exposto é simples aduzir que o recurso discursivo à individualidade do autor só é capaz de fornecer soluções que satisfaçam os interesses da/das parte/partes individuais envolvidas em conflitos que versem sobre o direito de autor, deixando à margem o elemento cultural, a contrapartida pelo custo social gerado pela intervenção do legislador no estado natural da informação. 
$\mathrm{Eu}$ noto que, enquanto a informação foi um mero acessório na estrutura de organização econômica das sociedades, não se fizeram sentir de forma aguda as consequências da postura estritamente individualista de aplicação do direito de autor, em ignorância do instrumental de fomento cultural do instituto jurídico, o que implicaria necessariamente na consideração da criação intelectual como um elemento de um processo comunicativo dinâmico. A transformação na estrutura econômica moderna, que trouxe a informação ao centro de sua organização, e a revolução nas tecnologias de comunicação, que ampliaram o espectro das possibilidades de compartilhamento de conteúdos, exige, porém, que a aplicação do direito de autor se afaste do discurso tradicional aqui criticado, e que tenha a obra em consideração àquilo que ela é: não a expressão da individualidade de alguém, mas uma expressão comunicativa e, por isso (e só por isso) culturalmente valorosa.

Assim atualizado e equilibrado, fazendo jus ao valor cultural da criação intelectual como limite dos interesses individuais, um discurso reformado voltado a legitimar a proteção exclusiva garantida pelo direito de autor, ao contrário do que vem alcançando a argumentação dualistaindividual tradicional, poderá influenciar positivamente $\mathrm{o}$ processo de formação de convencimento jurídico dos destinatários, um convencimento que - é impossível negar - hoje não encontramos junto aos destinatários das normas autorais.

Artigo recebido em 01/06/11 e aprovado em 18/06/11.

\section{Referências}

CARBONI, Guilherme. Direito autoral e autoria colaborativa na economia de informação em rede. São Paulo: Quartier Latin (2010)

FOUCAULT, Michel. Was ist ein Autor?, in Texte zur Literaturtheorie der Gegenwart, Org. KRIMMICH, Dorothee/RENNER, Rolf G./STIEGLER, Bernd. Stuttgart: Reclam (1996), 232247.

MUKAROWSKY, Jan. Die Persönlichkeit in der Kunst, in Texte zur Theorie der Autorschaft, Org., JANNIIDIS, Fotis/LAUER, Gerhard/ MARTINEZ, Matias/ WINKO, Simone Stuttgart: Reclam (2000), 65-79.

RÜTHERS, Bernd. Rechtstheorie, $2^{\mathrm{a}}$ Edição, München: C.H. Beck, 2005 
TOMASEVSKIJ, Boris. Literatur und Biographie, in Texte zur Theorie der Autorschaft, Org, JANNIIDIS, Fotis/LAUER, Gerhard/ MARTINEZ, Matias/ WINKO, Simone Stuttgart: Reclam (2000), 49-61. 